\title{
The effect of the global UV irradiance measurement accuracy on the single scattering albedo retrieval
}

\author{
S. Kazadzis ${ }^{1}$, J. Gröbner ${ }^{2}$, A. Arola ${ }^{3}$, and V. Amiridis ${ }^{4}$ \\ ${ }^{1}$ Institute for Environmental Research and Sustainable Development, National Observatory of Athens, Greece \\ ${ }^{2}$ Physikalisch-Meteorologisches Observatorium Davos, World Radiation Center, Davos, Switzerland \\ ${ }^{3}$ Finnish Meteorological Institute, Kuopio Unit, Finland \\ ${ }^{4}$ Institute for Space Applications and Remote Sensing, National Observatory of Athens, Greece
}

Received: 17 March 2010 - Published in Atmos. Meas. Tech. Discuss.: 29 March 2010

Revised: 28 July 2010 - Accepted: 30 July 2010 - Published: 12 August 2010

\begin{abstract}
The possibility of measuring aerosol optical absorption properties in the UV spectral range such as single scattering albedo (SSA), using remote sensing techniques, is currently an open scientific issue. We investigate the limitations on calculating column average SSA using a combination of global UV spectral measurements (that are comon in various UV monitoring stations worldwide) with radiative transfer modeling. To point out the difficulties in such a retrieval we have used the travelling reference spectroradiometer QASUME (Quality Assurance of Spectral Ultraviolet Measurements in Europe) results from 27 visits to UV monitoring stations around Europe. We have used the QASUME instrument as relative reference, analyzing absolute differences and also temporal and spectral deviations of UV irraidances, that are used as basic input for the SSA retrieval.

The results comparing the mean SSA derived by all instruments, measuring synchronous UV spectra, showed that 5 were within \pm 0.02 difference from the SSA calculated from the QASUME instrument, while 17 were within \pm 0.04 , for the Solar zenith angle of 60 degrees. As for the uncertainty that has been calculated using the $2 \sigma$ standard deviation of the spectral measurements, a mean 0.072 and $0.10(2 \sigma)$ uncertainties have been calculated for $60^{\circ}$ and $30^{\circ}$, respectively. Based on the fact that additional uncertainties would be introduced in the SSA retrieval from AOD model input accuracy, assymetry parameter assumptions, we show that only very few instrumnents could be able to detect long term SSA changes. However, such measurements/results ar useful in order to retrieve SSA at UV wavelengths, a product needed for various applications such as, inputs for modeling radiative forcing studies and satellite retrieval algorithms.
\end{abstract}

Correspondence to: S. Kazadzis

(kazadzis@meteo.noa.gr)

\section{Introduction}

Aerosols affect the Earth's radiative balance both directly and indirectly (e.g. Charlson et al., 1992). Even though the understanding of direct effects is higher than that of indirect effects (Rosenfeld and Lensky, 1998) there are still open issues, mainly related to the absorption component by complex mixtures of aerosols in highly diverse environments. A comprehensive review, was given by IPCC (2007) and Yu et al. (2006), describing an assessment of the aerosol direct effect, regarding both the current status and those issues that still urgently require further research. Both emphasize, that the significant uncertainties in global columnar single scattering albedo (SSA) may constitute the largest single source of uncertainty in the current modeling estimates of aerosol climate forcing. SSA is the ratio of scattering to total extinction (scattering plus absorption). Since both quantities depend strongly on chemical composition, particle size, state of mixture, relative humidity and wavelength, comprehensive measurements are crucial to reduce SSA uncertainties propagated into aerosol radiative forcing estimates. However, the SSA is still very difficult to measure by ground based or satellite remote sensing techniques and in-situ methods (Corr et al., 2009). A large portion of this difficulty emerges from current weakness to account for accurate aerosol absorption measurements (AAPCI, 2009; Bergstrom et al., 2007).

The above discussion applies even more for aerosol absorption measurements at wavelengths in the UV part of the spectrum. Improvement in measurement and understanding of aerosol absorption in the UV (and parameters like SSA), that are currently used in various scientific applications based on theoretical assumptions, will significantly benefit to applications such as:

Published by Copernicus Publications on behalf of the European Geosciences Union. 
1. Aerosol effects on photochemical smog production: aerosol absorption, contrary to scattering, decreases photolysis rates of ozone production as it alters the amount of UV radiation available for chemical reactions within and below the aerosol layer (Dickerson et al., 1997).

2. Aerosol effects on UV trends may affect stratospheric ozone change: as current future scenario simulations of global UV levels are based on ozone recovery scenarios. In addition to this, the tendency for reduced anthropogenic aerosols in the atmosphere observed in the US and Europe during the last decade have to include not only AOD changes for characterizing possible aerosol trends, but also absorbing aerosol properties' changes.

3. Solar irradiance satellite retrieval algorithms are directly affected by the presence of absorbing aerosols: The discrepancies between ground-based UV measurements and satellite-derived (OMI, TOMS) are directly related with aerosol absorption not accounted for in the satellite retrieval algorithms (e.g. Kazadzis et al., 2009).

4. Commonly used atmospheric, radiative transfer applications and codes: as UV related radiative transfer algorithms suffer in precision due to large uncertainties in the input parameters of absorbing aerosol properties (e.g. van Weele et al., 2000).

The most common method for the determination of aerosol optical properties like SSA in the visible spectral range using measurements of sun and sky radiances by sun photometers and radiometers have been introduced to the Aerosol Robotic Network (AERONET - http://aeronet.gsfc.nasa.gov/), (Holben et al., 1998). It is based on the retrieval of aerosol optical and microphysical properties using inversion techniques applied to observations of the angular distribution of sky radiances of spectral AOD at visible and near infrared wavelengths demonstrated by Dubovik et al. (2002). Kassianov et al. (2005) has proposed measurements of direct and diffuse irradiance combined with radiative transfer modeling (RTM) for the retrieval of SSA. In addition, Krotkov et al. (2005a) has introduced a method based on the combination of colocated AERONET extinction measurements with Multi Filter Radiometer diffuse and global transmittances. The use of such methods for the determination of SSA in the ultraviolet are difficult due to enhanced molecular scattering and the effect of $\mathrm{NO}_{2}, \mathrm{O}_{3}$ and $\mathrm{SO}_{2}$ absorption (Krotkov et al., 2005b). In addition, irradiance and radiance measurements at UV wavelengths require more accurate instrument characterizations and accuracy of determining various, instrument related, parameters following guidelines for instrument specifications (Seckmeyer et al., 2001) and quality control procedures (Webb et al., 1998) such as: the wavelength and absolute calibration, the measurement signal to noise ratio, stray light effects and filters stability (Bais, 1997).
There are only few publications dealing with ground based measurement techniques for SSA retrieval at UV wavelengths from which column average absorption can be inferred using two basic methodologies to determine SSA. They both use UV measurements and AOD information as inputs in an RTM code. The first is using global spectral irradiances (GSI), (Kylling et al., 1998; Bais et al., 2005; Ialongo et al., 2010) and the second (Petters et al., 2003; Krotkov et al., 2005b) uses measurements of global and diffuse irradiance ratios (GDIR) from UV multi-filter rotating shadow-band radiometers. All, methods of inferring the SSA at UV wavelengths require that the sky be completely cloudless since the radiative transfer model calculations are made for cloudless conditions. Completely cloudless sky conditions are not a common occurrence at many geographical locations, and obviously the data must be screened to eliminate partial cloud cover situations. However, there are only a few publications including results of the validation of such methods (Krotkov et al., 2009). The main difference of these two approaches is that the GSI method requires accurate absolute radiation measurements (i.e. global irradiance) and the GDIR method requires dimensionless quantities (AOD, atmospheric transmittance). The two approaches require quite different calibration techniques. Most important is that both methods require accurate AOD and surface albedo for their use as input parameters in the RTM.

Taking into account the number of UV spectroradiometers (especially Brewer type) that are used for monitoring purposes worldwide (e.g. Bais et al., 2001; Gröbner et al., 2005), we aim to investigate the possibility using their measurements and their related accuracy in order to retrieve SSA at UV wavelengths. Such measurements with the use of the GSI method, can provide information on long term and short term SSA variability at various sites. In addition, it is an essential tool for radiative forcing studies (e.g. Hatzianastassiou et al., 2007; Kazadzis et al., 2009) or satellite retrieval algorithms (e.g. Arola et al., 2009). However, the GDIR method is impossible to be used for such purposes as only very few of such scanning instruments have the opportunity to measure both global and direct spectral irradiance. Even if practically Brewer spectroradiometers are able to perform such measurements (e.g. Kazadzis et al., 2005; Groebner and Meleti, 2004) only very few of them include them in their measuring schedule mainly due to difficulties to derive the absolute calibration of the direct spectral irradiance (Bais et al., 2005). In this work we are investigating the limitations and the level of SSA retrieval accuracy through global UV measurements (GSI method). Final aim is to assess the retrieval accuracy in order to investigate the possibility of using such measurements for deriving time series of aerosol absorption characteristics through the calculation of SSA. 


\section{Instrumentation and data}

\subsection{Spectral UV measurements}

In order to achieve the above mentioned goals we have used the European travelling reference spectroradiometer (QASUME) results during the years 2002-2005. We have to point out that this instrument was used in this work as a relative global irradiance standard and not as an absolute irradiance standard, measuring with strict protocols and maximum control effort for the period of the EU project QASUME (lap.physics.auth.gr/QASUME). Its measurements were used in order to analyze absolute differences and deviations of synchronized global irradiance measurements measuring in parallel, at the same atmospheric conditions, with 27 UV monitoring spectroradiometers (Gröbner et al., 2006).

The QASUME instrument is a part of the European U1traviolet Calibration Center that aims to improve the data quality in the European Global Atmospheric Watch UV network, to harmonize the results from different stations and monitoring programs, in order to ensure representative and consistent UV radiation data on a European scale. The transportable instrument approach was the main idea behind the EU project QASUME (2002-2004). The main idea behind this project was, that despite the progress made in the various inter-comparison exercises since 1991 (e.g. Bais et al., 2000; Webb et al., 2003), this inter-comparison process has several limitations and faults as a means of quality assurance (Bernhard and Seckmeyer, 1999). The QASUME reference spectroradiometer system has been previously described in detail in Gröbner et al., 2005. During the period of the QASUME project, 27 UV monitoring sites were visited with the transportable QASUME reference spectroradiometer. The instruments that have been visited consisted of 20 double and 7 single monochromators. Fifteen of them were Brewer type spectroradiometers that are more easily comparable as they are used nearly the same way at all stations. Their absolute scale calibration procedures are based on measurements of calibrated 1000W DXW lamp sources and each individual local operator was responsible for the post correction data procedures including angular response (cosine correction) procedures (11 out of 17), stray light and wavelength shift corrections. Ten instruments were using Bentham double monochromators having similarities mainly on focal length of the monochromator and the entrance optics which have been manifactured to have a close to ideal $(<1 \%$ for $\mathrm{SZA}<75^{\circ}$ ) angular response so they did not apply any cosine corrections. The two remaining instruments were a Jobin Yvonne and Dilor double monochromators with flat teflon as entrence optics, applying a cosine correction procedure.

A summary of the sites and the site instruments can be found in Table 1 and Fig. 1 of Groebner et al. (2006). The protocol of the measurements at each site are described in detail in Gröbner et al. (2003a, b, and 2004b). In addition all in- dividual visits of the QASUME instrument are accompanied by a scientific audit of achievements, problems and a final assessment for each visited site. All the audit-documents can be found at: http://www.pmodwrc.ch/euvc/euvc.php?topic= qasume_audit.

\subsection{SSA retrieval}

The attenuation of solar UV irradiance reaching the earth's surface by aerosols is mainly linked with aerosol optical properties such as AOD and SSA and in addition depends on solar zenith angle (SZA) at the time of the measurement. To demonstrate this effect in Fig. 1 we have calculated with the help of LibRadTran (Mayer and Kylling, 2005) radiative transfer code this attenuation for two solar zenith angles. Using such results and based on the methodology of Bais et al. (2005), we have constructed look up tables (LUT) of this UV attenuation as a function of AOD, SSA and SZA. The phase function that has been used in the analysis was 0.72 and surface albedo of 0.03 at $340 \mathrm{~nm}$ for all the calculations in this work. With the help of these LUT's (as described in the GSI method) someone can calculate the SSA which matches a measured UV attenuation for certain (also measured) AOD at a given SZA (Bais et al., 2005). It is clear from Fig. 1 that for higher solar zenith angles the attenuation for the same AOD's and SSA's is higher. So the uncertainty of the GSI method decreases for higher SZA's and AOD's and for lower SSA's. However, for instruments that have no ideal angular response of their input optics and do not apply any correction procedures, cosine response errors, that are larger for higher SZA's, would bias the UV irradiance measurements and therefore bias the SSA retrieval.

In this work we are aiming to investigate realistic (with the use of QASUME campaign results) limitations in the accuracy for the SSA retrieval using the GSI method linked with the spectroradiometer's global irradiance measurement's deviations. In all the 27 inter-comparison campaigns, the UV monitoring spectroradiometers have been visited by the QASUME instrument in order to analyze possible sources of UV measurement deviations at each visited site. More specifically we have used these results in order to investigate how absolute differences and standard deviation of the intercomparison periods could affect the GSI method for SSA retrieval. In Fig. 2 we have summarized the mean differences and the $2 \sigma$ (standard deviation) of all visiting instruments shown as ratios of any instrument with the QASUME at two UV wavelengths. Results shown in Fig. 2 represent mean irradiance differences at $310-325 \mathrm{~nm}$ (UVB) and $325-350 \mathrm{~nm}$ (UVA).

As it is shown in the above Fig. 2, 23 out of 27 instruments mean differences are within $\pm 5 \%$ compared with the QASUME instrument. In addition, deviations from this mean difference are shown. The reasons of such deviations of two spectroradiometers measuring side by side and performing synchronized spectral measurements are described in detail 

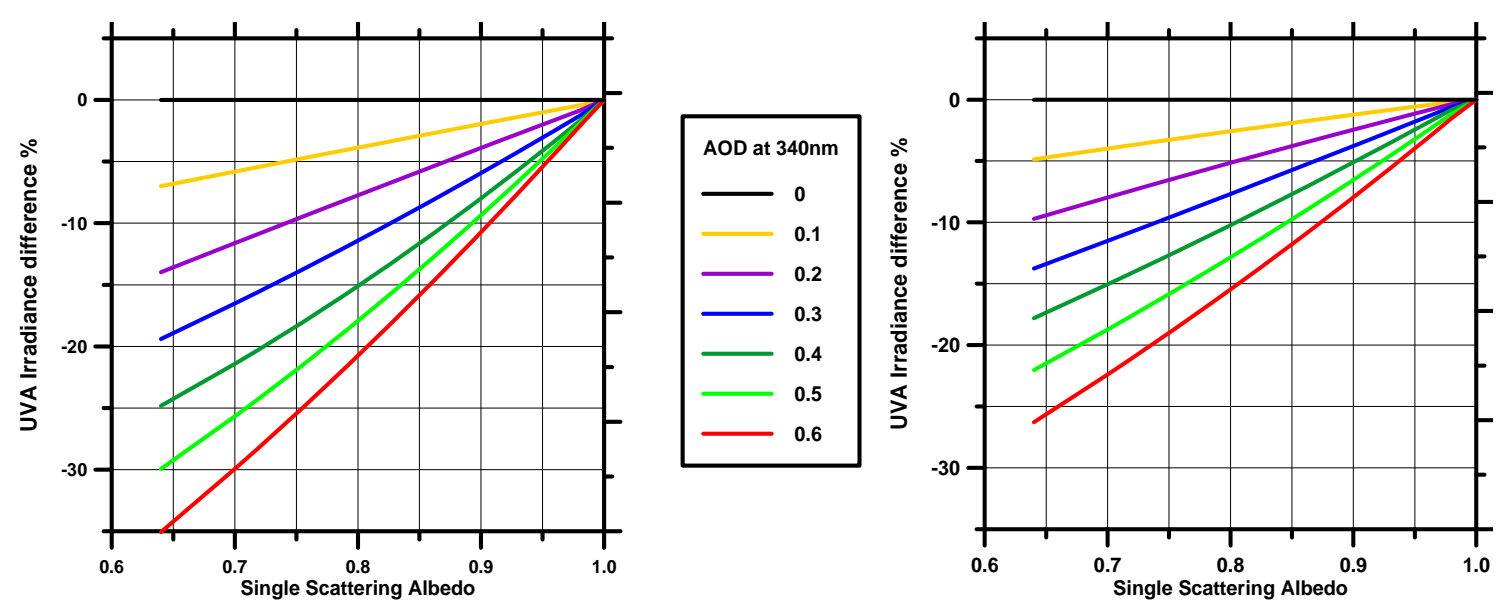

Fig. 1. Per cent irradiance difference from the irradiance using SSA $=1$ as a function of AOD's for SZA's of $60^{\circ}$ (left) and $30^{\circ}$ (right).

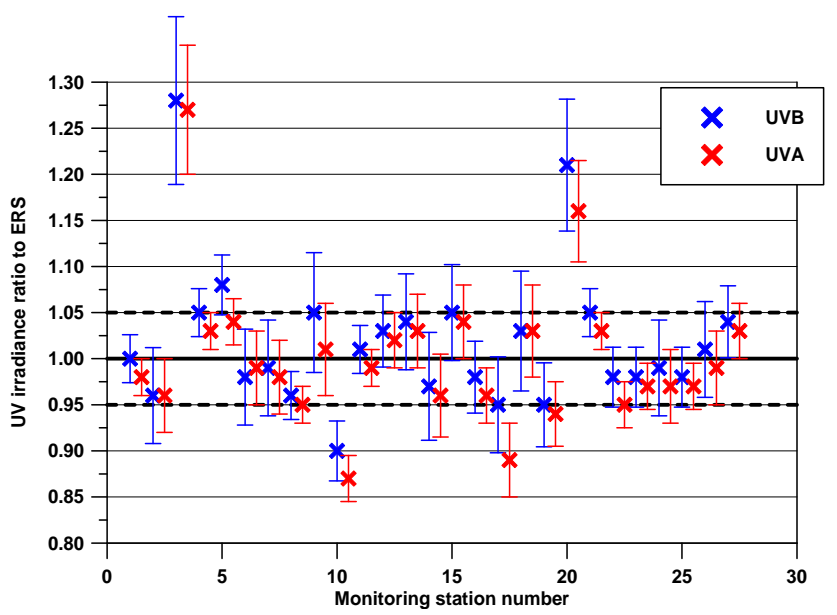

Fig. 2. Mean differences and the $2 \sigma$ (standard deviation) of all 27 visiting instruments shown as ratios of any instrument with the QASUME at UVB and UVA wavelengths.

in Bais et al. (1997 and 2000), Gröebner et al. (2004 and 2005). More specific concerning absolute irradiance differences: The standard deviations of the 27 instruments compared with the QASUME instrument of $3 \%$ in the UVA and $4 \%$ in the UVB can be mainly explained by the uncertainties of the irradiance standards and their documented differences. If the instruments are split into two groups, those with stateof-the-art entrance optics with low cosine errors and those that apply a cosine correction on the one hand, and the remaining instruments on the other hand, the average variability of $5.9 \%$ for the first group is significantly lower than the variability of $7.6 \%$ of the second group of instruments, which can be explained by the known and observed diurnal variations induced by a non ideal angular response. Concerning wavelength shift errors: The largest average wavelength shifts of up to $0.3 \mathrm{~nm}$ are seen with a Bentham spectrora- diometer, while the worst case for a Brewer spectroradiometer has a wavelength shift of $0.06 \mathrm{~nm}$. So Brewer spectroradiometers using their standard operating procedures appear to have a much lower wavelength uncertainty than most other spectroradiometers in this study. Concerning stray light errors: Only single Brewers showed such problems showing average (as the following percentages are SZA and ozone dependent) stray light contribution of 1\% and $11 \%$ for $305 \mathrm{~nm}$ and $302 \mathrm{~nm}$ irradiances, respectively.

The instruments at each campaign were measuring about 20-30 spectral measurements per day for a period of 2-4 days depending on the site. The results used here could be used as a unique realistic example of the accuracy of such measurements in a very well organized campaign.

The analysis in order to investigate the uncertainty budget in order to calculate SSA using the GSI method was based on the:

1. Absolute mean difference of the two spectroradiometers

2. Standard deviation of the differences during the intercomparison period

The methodology used in order to calculate the difference in the retrieved SSA from the two instruments was the following:

The LUT's calculated with the LibRadTran RTM were used, with input parameters: the spectral measurements of each instrument, the solar zenith angle of every measurement and an AOD (for each location and for the specific month of the measurement campaign) based on the aerosol Climatology database of AeroComm (Kinne et al., 2009). The AOD that was used was constant during the whole campaign period at each site. This was decided, as the main interest of this work was to calculate the SSA retrieval uncertainty only from UV spectral measurement deviations and not to mix other sources of uncertainties such as ones related with RTM input parameters. The latest will also be discussed in 


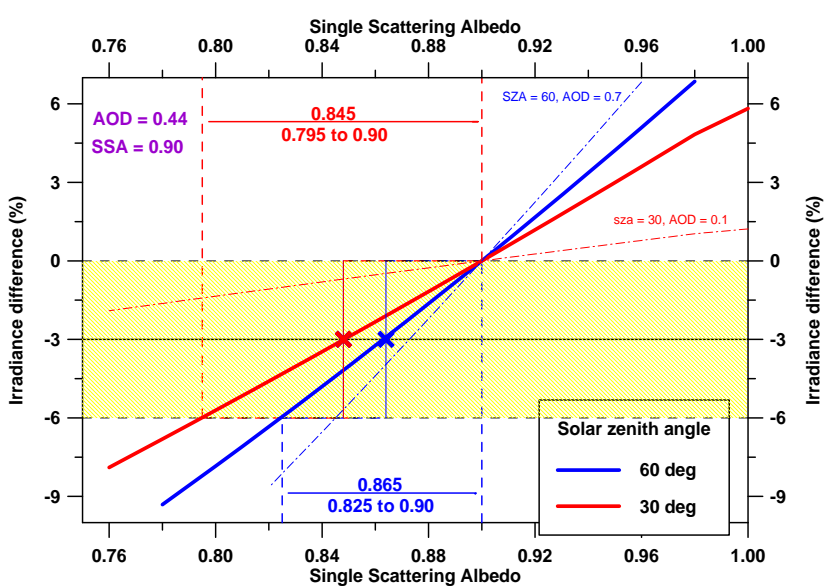

Fig. 3. Retrieval GSI methodology for calculating effective SSA.

the conclusion section. In addition, synchronized AOD measurements were not available for a number of the sites analyzed.

The methodology for calculating SSA from global UV irradiance measurements is illustrated in Fig. 3. There, as an example a $-3 \%$ difference and a $3 \%(2 \sigma)$ standard deviation between the QASUME and a specific spectroradiometer (SP) at $340 \mathrm{~nm}$ have been used (crosses), with an AOD of 0.44 and an SSA of 0.9, for two different solar zenith angles of $30^{\circ}$ and $60^{\circ}$ (red and blue line respectively). The figure shows that for the case of $60^{\circ}$ the instrument SP would lead to an SSA calculation from 0.825 to 0.9 with a mean value of 0.865 . Similar for $30^{\circ}$ it would calculate an SSA from 0.795 to 0.9 with a mean of 0.845 .

AOD and irradiance differences shown here were chosen as they were the mean values for the 27 sites analyzed. However, Fig. 3 is just used as an example to demonstrate visually the methodology used here. Dash lines represent other AOD values. It is shown that higher AOD values (blue dash line with an AOD of 0.7 at $340 \mathrm{~nm}$ ) lead to better accuracy for the SSA retrieval, while very low AOD values (red dash line with an AOD of 0.1 at $340 \mathrm{~nm}$ ) lead to a very high uncertainty. The same procedure has been repeated with all instruments for the UVB (310-325 nm) and UVA (325-360 nm) spectral range using the results demonstrated in Fig. 2.

\section{Results and conclusions}

As shown in Fig. 2 there were 4 instruments that showed mean deviations outside the $\pm 5 \%$ area compared with the QASUME instrument. Such deviations were due to calibration problems or instrument failures at the time of the inter-comparison so we have excluded them from the following statistical analysis. The results of the 23 remaining stations comparing the mean SSA derived by both instruments showed that 5 out of 23 were within \pm 0.02 difference

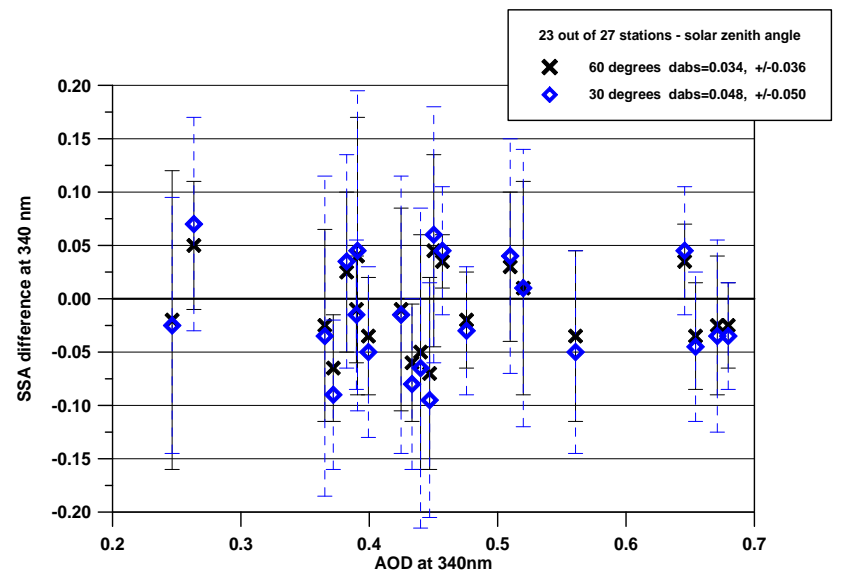

Fig. 4. Results of SSA differences between each SP and the Qasume instrument for two solar zenith angles as a function of AOD used for each station.

from the QASUME instrument, while 17 were within \pm 0.04 for the SZA of 60 degrees. As for the uncertainty that has been calculated using the $2 \sigma$ standard deviation of the spectral measurements, a mean 0.072 and $0.10(2 \sigma)$ uncertainties have been calculated for $60^{\circ}$ and $30^{\circ}$, respectively. The results from the 23 stations are shown in Fig. 4.

The differences in the mean value but also the $2 \sigma$ deviations shown in Fig. 4 are affected from various factors. Main factor is the absolute difference and the standard deviation of the global spectral UV irradiance measurements between each instrument and the QASUME instrument. It has to be clarified that the QASUME instrument is not used here as the "absolute truth" concerning absolute irradiance UV measurements, but mainly as a stable, quality assured instrument, that can determine relative deviations among the instruments operating at the visited UV monitoring stations around Europe. Also, an instrument that can be used for homogenizing both UV spectral measurements around Europe but also byproducts such as the SSA retrieval presented here. Analyzing the results at each site, the SSA deviations are affected by the different optical path inside the aerosol layer (SZA effect) and the absolute AOD value used for each site. This last factor shows that for cases of sites with low AOD's the retrieval of SSA becomes highly uncertain. Similar results for one site has been presented in Bais et al. (2005).

The SSA retrievals from results based on measurements of spectroradiometers with a non ideal angular response of their input optics are likely to be biased as measured UV irradiance is lower than true values at large SZA's resulting lower inferred SSA than true values of SSA. For the case of the QASUME reference instrument and the majority (20 out of 27 instruments) this is not the case as they are either equipped with ideal in terms of angular response input optics or they apply correction procedures in order to eliminate such errors. 
Moreover, for the proposed method there are additional sources of errors in the SSA calculations at a particular site. They include the uncertainty of RTM input parameters such as:

- AOD measurement: Calibrated sun-photometers can provide AOD measurements with an uncertainty of 0.01-0.02 (Eck et al., 1999). Using satellite aerosol AOD information or other model based AOD databases, the uncertainty increases due to spatial AOD features especially at urban areas and temporal AOD variability that can not be easily provided with these means. In addition, using AOD information from measurements at the visible range and extrapolating to the UV wavelength range using an Angstrom exponent introduces an additional uncertainty due to non-linearity in the AOD versus wavelength relationship (Eck et al., 1999).

- Assymetry parameter, aerosol profile and extraterrestrial spectrum uncertainties: for the comparison of all spectroradiometers with the QASUME and ths SSA retrieval we have used the same aerosol optical parameters for both instruments. So, the present methodology does not include information on the uncertainty included from such issues as their availability depend on the additional instrumentation of the individual UV monitoring site, that this methodology could be applied. For each site there is a need for a methodology to select appropriate values of spectral asymmetry factors that are representative of differing aerosol size distributions such as coarse mode desert dust or fine mode pollution or mixtures of the two. For example the presence of a sun-photometer (AERONET or other Network based), together with the UV irradiance spectroradiometer minimizes such uncertainties.

- A recent study (Ialongo et al., 2010) has been using the GSI method for the retrieval of SSA using UV global spectral measurements at solar (local) noon. In such studies due to the SZA variations during the year and also due to the AOD annual variations, the uncertainty for calculating the SSA is not constant (proportional to UV global irradiance measurement uncertainties), but depends on the SZA and AOD of each individual retrieval.

It has been mentioned that the calculation of the colunmar (effective) SSA using the GSI or the GDIR method are at the moment the only existing methods for calculating this parameter in the UV region. It is clear that the method of Krotkov et al. (2005a) which is based on direct-diffuse ratio, has a significant advantage over the technique of using total UV irradiance due to the uncertainty in the irradiance measurements resulting from the calibration uncertainty. However, we decided to analyze the possibilities to use the GSI method because of the large number of UV monitoring station that have been performing global UV measurements from the start of the 1990s. On the contrary only very few stations (starting also after the year 2000) are equiped with the instruments that the GDIR method can be applied. So, only results from the GSI method can be used in order to investigate possible long term SSA changes in a number of locations worldwide, when UV irradiance measurements are accompanied by accurate AOD measurements. Such changes can enlarge or diminish the effects of AOD changes in UV radiative forcing. Recent studies especially for Europe and North America showed a certain decrease of AOD values (Norris and Wild, 2009; Ohmura, 2009; Ruckstuhl and Norris, 2009). In parallel with the AOD effects, possible changes to aerosol absorption parameters would have also an additional feedback/effect on the calculated UV irradiance increase.

The results shown here demonstrate the possibility to use the retrieved SSA using the GSI method for aerosol related studies. For example for exploring aerosol absorption trends in the UV, only few instruments around Europe could be used to achieve this goal. However, even most accurate measurements using the GSI method can not provide accurate SSA retrievals (i.e. within 0.03) without accurate (i.e. within 0.01) AOD measurements. This is demonstrated by the fact that the mean difference and the $2 \sigma$ variability of the SSA retrieval among two synchronized instruments is in the order of the magnitude of the possible trends that could be detected. For regional or global radiative forcing studies in the UV region, such measurements accompanied with their uncertainty, become very important as they are the only existing methodology at this point. Also, there is need for ground based measurements/algorithms than could provide independent measurements of SSA in the UV in order to assess the accuracy of satellite derived SSA by the Ozone Monitoring Instrument (OMI) observations (Torres et al., 2007). In addition, satellite aerosol and radiation retrieval algorithms could use such time series in order to improve the aerosol absorption assumptions used as input optics in their retrieval schemes. As an example the Ozone Monitoring Instrument (on board of Aura satellite) surface UV retrieval recently introduced a post correction methodology that needs aerosol effective SSA worldwide (Arola et al., 2009).

Finally, the data used here are the results of very well organized inter-comparison campaigns of very sophisticated spectral instruments. The direct comparison of two well characterized instruments measuring synchronous UV measurements under the same conditions and having the maximum effort from the local operators are making this comparison results the best available in terms of data quality. Such results were used here as a tool in order to realistically assess the possibilities of the SSA retrieval. Based on the above facts, any operator of other (broadband or filter) instruments that measure global UV irradiance has to put much more effort in order to reach the absolute accuracy/long term stability, similar to the spectroradiometers, in order to retrieve SSA with similar uncertainty budget. 
Summarizing, this work focuses on the possibility to use long term series of UV global irradiance measurements, in order to derive information on the SSA at various locations. Using comparison results of well organized campaigns we aimed to show realistic instrument differences, linked with absolute calibration, angular response and other measurement uncertainties. The uncertainty of deriving SSA from such measurements described, are linked not only with the measurement accuracy but also with the availability to use accurate RTM input parameters such as AOD, surface albedo, asymmetry parameter, ozone, $\mathrm{NO}_{2}$. Other studies showed that using speciffic instruments or combination of instruments that can provide accurate knowledge of dimensionless transmittance, is sufficient for deriving SSA with a provided uncertainty. However, the value of this work/investigation is based on the fact that the number of spectroradiometers (or even UV broadband radiometers) providing absolute UV irradiance measurements from the start of the 1990s, could be used for the retrieval of aerosol SSA time series worldwide, with an uncertainty depending on each individual instrument. In addition, it has to be mentioned that the uncertainty of this retrieval is also influenced by the availability of measurements or accurate assumption of other RTM input parameters, mentioned above. As an example, the Brewer spectroradiometer Network could provide a valuable database of spectral UV measurements together with AOD retrieval (using their standard direct sun ozone measurement) in order to provide SSA information with relatively high spatial and temporal coverage.

Acknowledgements. SK would like to acknowledge Marie Curie project ACI-UV, PERG05-GA-2009-247492. The authors would like thank the anonymous reviewers for their crucial comments that improved this work.

Edited by: O. Torres

\section{References}

Arola, A., Kazadzis, S., Lindfors, A., Krotkov, N., Kujanpaa, J., Tamminen, J., Bais, A., di Sarra, A., Villaplana, J. M., Brogniez, C., Siani, A. M., Janouch, M., Weihs, P., Koskela, T., Kouremeti, N., Meloni, D., Buchard, V., Auriol, F., Ialongo, I., Staneck, M., Simic, S., Webb, A., Smedley, A., and Kinne, S.: A new approach to correct for absorbing aerosols in OMI UV: a preliminary evaluation, Geophys. Res. Lett., 36, L22805, doi:10.1029/2009GL041137, 2009.

Atmospheric Aerosol Properties and Climate Impacts (AAPCI): Synthesis and Assessment Product Report by the U.S. Climate Change Science Program and the Subcommittee on Global Change Research, edited by: Chin, M., Kahn, R., Remer, L., Yu, H., Rind, D., Feingold, G., Quinn, P., Schwartz, S., Streets, D., and Halthore, R., 2009.

Bergstrom, R. W., Pilewskie, P., Russell, P. B., Redemann, J., Bond, T. C., Quinn, P. K., and Sierau, B.: Spectral absorption properties of atmospheric aerosols, Atmos. Chem. Phys., 7, 5937-5943, doi:10.5194/acp-7-5937-2007, 2007.
Bais, A. F., Gardiner, B. G., Slaper, H., Blumthaler, M., Bernhard, G., McKenzie, R., Webb, A. R., Seckmeyer, G., Kjeldstad, B., Koskela, T., Kirsch, P., Gröbner, J., Kerr, J. B., Kazadzis, S., Leszczynski, K., Wardle, D., Brogniez, C., Josefsson, W., Gillotay, D., Reinen, H., Weihs, P., Svenoe, T., Eriksen, P., Kuik, F., and Redondas, A.: SUSPEN intercomparison of ultraviolet spectroradiometers, J. Geophys. Res., 106, 12509-12526, 2001.

Bais, A.: Spectrometers: operational errors and uncertainties, in: Solar Ultraviolet Radiation Modeling, Measurements and Effects, edited by: Zerefos, C. S. and Bais, A. F., vol. 52 of NATO ASI Series I, Global Environmental Change, Springer-Verlag, Berlin, pp. 163-173, 1997.

Bais, A. F., Kazantzidis, A., Kazadzis, S., Balis, D. S., Zerefos, C. S., and Meleti, C.: Deriving an effective aerosol single scattering albedo from spectral surface UV irradiance measurements, Atmos. Environ., 39(6), 1093-1102, 2005.

Bais, A. F., Blumthaler, M., Webb, A., Seckmeyer, G., Thiel, S., Kazadzis, S., Redondas, A., Kift, R., Kouremeti, N., Schallhart, B., Schmitt, R., Pisulla, D., Diaz, J. P., Garcia, O., Diaz, A., Rodriguez, M., and Smedley, A.: Intercomparison of solar UV direct irradiance spectral measurements at Izana in June 2005, in: Ultraviolet Ground- and Space-based Measurements, Models, and Effects V, Proc. SPIE, 5886, San Diego, USA, 31 July-4 August 2005, edited by: Bernhard, G., Slusser, J. R., Herman, J. R., and Gao, W., pp. 1-10, 2005.

Bernhard, G. and Seckmeyer, G.: Uncertainty of measurements of spectral solar UV irradiance, J. Geophys. Res., 104, 1432114345, 1999.

Charlson, R. J., Schwartz, S. E., Hales, J. M., Cess, R. D., Coakley Jr., J. A., Hansen, J. E., and Hofmann, D. J.: Climate forcing by anthropogenic aerosols, Science, 255, 423-430, 1992.

Corr, C. A., Krotkov, N., Madronich, S., Slusser, J. R., Holben, B., Gao, W., Flynn, J., Lefer, B., and Kreidenweis, S. M.: Retrieval of aerosol single scattering albedo at ultraviolet wavelengths at the T1 site during MILAGRO, Atmos. Chem. Phys., 9, 58135827, doi:10.5194/acp-9-5813-2009, 2009.

Dickerson, R. R., Kondragunta, S., Stenchikov, G., Civerolo, K. L., Doddridge, B. G., and Holben, B. N.: The impact of aerosols on solar Ultraviolet radiation and photochemical smog, Science, 28, 827-830, 1997.

Dubovik, O., Holben, B., Eck, T. F., Smirnov, A., Kaufman, Y. J., King, M. D., Tanré, D., and Slutsker, I.: Variability of absorption and optical properties of key aerosol types observed in worldwide locations, J. Atmos. Sci., 59, 590-608, 2002.

Eck, T. F., Holben, B. N., Reid, J. S., Dubovik, O., Smirnov, A., O'Neill, N. T., Slutsker, I., and Kinne, S.: Wavelength dependence of the optical depth of biomass burning, urban, and desert dust aerosols, J. Geophys. Res., 104, 31333-31349., 1999.

Gröbner, J., Kazadzis, S., Schreder, J., Bais, A. F., Blumthaler, M., Görts, P., Koskela, T., Seckmeyer, G., Webb, A. R., and Wuttke, S.: Quality assurance of spectral ultraviolet measurements in Europe through the development of a transportable unit (QASUME) - Report of site visits, Round 2002 EUR 20991 EN European Commission, 2003a.

Gröbner, J., Schreder, J., Kazadzis, S., et al.: Quality assurance of spectral ultraviolet measurements in Europe through the development of a transportable unit (QASUME) - Report of site visits, Round 2003 EUR 20992 EN European Commission, 2003b. 
Gröbner, J. and Meleti, C.: Aerosol optical depth in the UVB and visible wavelength range from Brewer spectrophotometer direct irradiance measurements: 1991-2002, J. Geophys. Res., 109, D09202, doi:10.1029/2003JD004409, 2004a

Gröbner J., Schreder, J., Kazadzis, S., et al.: Quality assurance of spectral ultraviolet measurements in Europe through the development of a transportable unit (QASUME) - Report of site visits, Round 2004 EUR 21398 EN European Commission, 2004b.

Grobner, J., Schreder, J., Kazadzis, S., Bais, A. F., Blumthaler, M., Gorts, P., Tax, R., Koskela, T., Seckmeyer, G., and Webb, A. R.: A travelling reference spectroradiometer for routine quality assurance of spectral solar ultraviolet irradiance measurements, Appl. Optics, 44(25), 5321-5331, 2005.

Gröbner, J., Blumthaler, M., Kazadzis, S., Bais, A., Webb, A., Schreder, J., Seckmeyer, G., and Rembges, D.: Quality Assurance of spectral solar UV measurements: results from $25 \mathrm{UV}$ monitoring sites in Europe, 2002 to 2004, Metrologia, 43, 6671, doi:10.1088/0026-1394/43/2/S14, 2006.

Hatzianastassiou, N., Matsoukas, C., Drakakis, E., Stackhouse Jr., P. W., Koepke, P., Fotiadi, A., Pavlakis, K. G., and Vardavas, I.: The direct effect of aerosols on solar radiation based on satellite observations, reanalysis datasets, and spectral aerosol optical properties from Global Aerosol Data Set (GADS), Atmos. Chem. Phys., 7, 2585-2599, doi:10.5194/acp-7-2585-2007, 2007.

Holben, B. N., Eck, T. F., Slutsker, I., Tanre, D., Buis, J. P., Setzer, A., Vermote, E., Reagan, J. A., Kaufman, Y. J., Nakajima, T., Lavenu, F., Jankowiak, I., and Smirnov, A.: AERONET - A federated instrument network and data archive for aerosol characterization, Rem. Sens. Environ., 66, 1-16, 1998.

Ialongo, I., Buchard, V., Brogniez, C., Casale, G. R., and Siani, A. M.: Aerosol Single Scattering Albedo retrieval in the UV range: an application to OMI satellite validation, Atmos. Chem. Phys., 10, 331-340, doi:10.5194/acp-10-331-2010, 2010.

IPCC, 2007: Climate Change 2007: The Physical Science Basis. Contribution of Working Group I to the Fourth Assessment Report of the Intergovernmental Panel on Climate Change Cambridge University Press, Cambridge, United Kingdom and New York, NY, USA, 996 pp, 2007.

Kassianov, E. I., Barnard, J. C., and Ackerman, T. P.: Retrieval of aerosol microphysical properties using surface Multifilter Rotating Shadowband Radiometer (MFRSR) data: Modeling and observations, J. Geophys. Res., 110, D09201, doi:10.1029/2004JD005337, 2005.

Kazadzis, S., Bais, A., Arola, A., Krotkov, N., Kouremeti, N., and Meleti, C.: Ozone Monitoring Instrument spectral UV irradiance products: comparison with ground based measurements at an urban environment, Atmos. Chem. Phys., 9, 585-594, doi:10.5194/acp-9-585-2009, 2009.

Kazadzis, S., Kouremeti, N., Bais, A., Kazantzidis, A., and Meleti, C.: Aerosol forcing efficiency in the UVA region from spectral solar irradiance measurements at an urban environment, Ann. Geophys., 27, 2515-2522, doi:10.5194/angeo-27-25152009, 2009.

Krotkov, N., Bhartia, P. K., Herman, J., Slusser, J., Labow, G., Scott, G., Janson, G., Eck, T. F., and Holben, B.: Aerosol ultraviolet absorption experiment (2002 to 2004), part 1: ultraviolet multifilter rotating shadowband radiometer calibration and intercomparison with CIMEL sunphotometers, Opt. Eng., 44, 041001, doi:10.1117/1.1886818, 2005a.
Krotkov, N., Bhartia, P. K., Herman, J., Slusser, J., Scott, G., Labow, G., Vasilkov, A. P., Eck, T. F., Dubovik, O., and Holben, B. N.: Aerosol ultraviolet absorption experiment (2002 to 2004), part 2: absorption optical thickness, refractive index, and single scattering albedo, Opt. Eng., 44, 041005, doi:10.1117/1.1886819, $2005 b$.

Krotkov, N., Labow, G., Herman, J., Slusser, J., Tree, R., Jason, G., Durham, B., Eck, T., Holben, B.: Aerosol column absorption measurements using co-located UV-MFRSR and AERONET CIMEL instruments, in: Ultraviolet Ground- and Space-based Measurements, Models, and Effects VI, edited by: Herman, J. R. and Wei Gao, Proceedings of SPIE, 7462, SPIE, Bellingham, WA, 2009.

Kylling, A., Bais, A. F., Blumthaler, M., Shreder, J., and Zerefos, C. S.: UV irradiances during the PAUR campaign: comparison between measurement and model simulations, J. Geophys. Res., 103(D20), 26051-26060, 1998.

Mayer, B. and Kylling, A.: Technical note: The libRadtran software package for radiative transfer calculations - description and examples of use, Atmos. Chem. Phys., 5, 1855-1877, doi:10.5194/acp-5-1855-2005, 2005.

Norris, J. R. and Wild, M.: Trends in aerosol radiative effects over China and Japan inferred from observed cloud cover, solar "dimming," and solar "brightening”, J. Geophys. Res., 114, D00D15, doi:10.1029/2008JD011378, 2009.

Ohmura, A.: Observed decadal variations in surface solar radiation and their causes, J. Geophys. Res., 114, D00D05, doi:10.1029/2008JD011290, 2009.

Petters, J. L., Saxena, V. K., Slusser, J. R., Wenny, B. N., and Madronich, S.: Aerosol single scattering albedo retrieved from measurements of surface UV irradiance and a radiative transfer model, J. Geophys. Res., 108(D9), 4288, doi:10.1029/2002JD002360, 2003.

Rosenfeld, D. and Lensky, I. M.: Satellite-Based Insights into Precipitation Formation Processes in Continental and Maritime Convective Clouds, B. Am. Meteorol. Soc., 79(11), 2457-2476, 1998.

Ruckstuhl, C. and Norris, J. R.: How do aerosol histories affect solar "dimming" and "brightening" over Europe?: IPCC-AR4 models versus observations, J. Geophys. Res., 114, D00D04, doi:10.1029/2008JD011066, 2009.

Seckmeyer, G., Bais, A., Bernhard, G., Blumthaler, M., Eriksen, P., McKenzie, R. L., Roy, C., and Miyauchi, M.: Instruments to measure solar ultraviolet radiation, part I: spectral instruments WMO-GAW Report Geneva, Switzerland, 2001.

Torres, O., Tanskanen, A., Veihelmann, B., Ahn, C., Braak, R., Bhartia, P. K., Veefkind, P., and Levelt, P.: Aerosols and surface UV products from Ozone Monitoring Instrument observations: An overview, J. Geophys. Res., 112, D24S47, doi:10.1029/2007JD008809, 2007.

Van Wheele, M., Martin, T., Blumthaler, M., et al.: From model intercomparison toward benchmark UV spectra for six real atmospheric cases, J. Geophys. Res., 105(D4), 4915-4925, 2000.

Webb, A. R., Gardiner, B. G., Martin, T. J., Leszcynski, K., Metzdorf, J., and Mohnen, V. A.: Guidelines for site quality control of UV monitoring, WMO-GAW Report No 126, Geneva, Switzerland, 1998.

Webb, A. R., Gardiner, B. G., Leszczynski, K., Mohnen, V., Johnston, P., Harrison, N., and Bigelow, D.: Quality assur- 
ance in monitoring solar ultraviolet radiation: state of the art WMO/GAW No. 146 World Meteorological Organisation, Geneva, 2003.
Yu, H., Kaufman, Y. J., Chin, M., Feingold, G., Remer, L. A., Anderson, T. L., Balkanski, Y., Bellouin, N., Boucher, O., Christopher, S., DeCola, P., Kahn, R., Koch, D., Loeb, N., Reddy, M. S., Schulz, M., Takemura, T., and Zhou, M.: A review of measurement-based assessments of the aerosol direct radiative effect and forcing, Atmos. Chem. Phys., 6, 613-666, doi:10.5194/acp-6-613-2006, 2006. 